\title{
HERBAL MEDICINES QUESTIONNAIRE AND EVALUATION OF ATTITUDE, PERCEPTIONS AND SELF-USE AMONG HEALTH CARE PROFESSIONALS IN RAK, UAE: PILOT STUDY
}

\author{
AMAD M. AL-AZZAWIa, NEHAD MEHDIb, ALYAA G. AL-JUBOORIc, ANAM EJAZd, HANEEN ALId, OMAR SARHEED
}

aRas Al Khaimah College of Pharmaceutical Sciences (RAKCOPS), Ras Al Khaimah Medical and Health Sciences University, Ras Al Khaimah (RAKMHSU), UAE, Currently, Toronto, Canada, bCollege of Pharmacy, GMC, Ajman, Previously, 'Department of General Education, Rakmhsu, UAE, Currently, Toronto, Canada, dNinth Semester Students of Rakcops, Rakmhsu, UAE. Currently Licensed Pharmacist, eRas Al Khaimah College of Pharmaceutical Sciences (RAKCOPS), Ras Al Khaimah Medical and Health Sciences University, Ras Al Khaimah (RAKMHSU), UAE

Email: imadazzawi@yahoo.co.uk

Received: 24 Sep 2018 Revised and Accepted: 04 Feb 2019

\section{ABSTRACT}

Objective: The aim of this study was to assess the perceptions of different healthcare professionals towards HM.

Methods: The 16-item questionnaire on the belief of health care professionals in herbal medicine was designed by the interdisciplinary task force. Eligible participants were health care providers who were English-and Arabic-literate. The response rate was 78\% of participants (781 of 1000) were respondents. In total, 553 out of $781(71 \%)$ participants indicated that they had previously used herbal medicines. The remaining 228 participants did not believe in herbal medicine due to lack of scientific evidence, ineffectiveness and other reasons.

Results: The findings of this study indicate that health care professionals including pharmacists believe they have a responsibility to provide information on HM to their patients. However, the current consensus among the respondents is that current HM-focused knowledge is inadequate for such an application.

Conclusion: Health care professionals believe in using HM for their needs and have a responsibility to provide information on HM to their patients.

Keywords: Complementary and Alternative Medicine, Questionnaire, Health Care Professionals, Attitude, Perceptions

(C) 2019 The Authors. Published by Innovare Academic Sciences Pvt Ltd. This is an open access article under the CC BY license (http://creativecommons.org/licenses/by/4.0/] DOI: http://dx.doi.org/10.22159/ijpps.2019v11i3.29945

\section{INTRODUCTION}

Complementary and alternative medicine (CAM) includes herbal medicine, acupuncture, chiropractic manipulation, meditation, homeopathy, and other approaches. According to WHO definition on herbal medicines (HM) "include herbs, herbal materials, herbal preparations and finished herbal products that contain as active ingredients parts of plants, or other plant materials, or combinations". The use of HM has become increasingly popular worldwide and it is often associated with self-administration [1]. Herbal medicines have sometimes been used in parallel with conventional medications with the precaution of drug-herbal interaction $[2,3]$.

Pharmacists are frequently regarded as health care practitioners with relatively high accessibility and integrity. As a result, patients routinely seek advice relating to the correct and optimal use of HM. This has led professionals within the pharmaceutical realm to question whether superior programs need to be developed for the facilitation of pharmacist education relating to $\mathrm{HM}[4,5]$. A number of literature reports have documented in a non-systematic way the knowledge, attitudes and perceptions of health care professionals towards HM. For example, Lisk indicated that very few health care professionals are aware of the use of HM [6, 7].

Shah et al. showed that students perceived that their knowledge relating to herbal supplements is inadequate in its current form and they desired the development of didactic courses to address this drawback [8]. Harris et al. found that pharmacy faculty members and students feel positive towards the general use of CAM [9]

In order to meet these educational challenges and develop effective educational programs relating to $\mathrm{HM}$, it is first necessary to gauge the knowledge base and beliefs of healthcare professionals towards these types of therapies. Only in so doing can educational leaders be able to focus their educational programs to reinforce or challenge practices in order to ensure best practice for patients.
There have also been studies which focused directly on recommendations to address the requirements in providing education about HM. One study proposed that professional pharmacy bodies should generate instructions on how to implement herbal education in curricula and that pharmacy schools should have a structured approach in teaching about herbal products [8] Lie and Boker highlighted the benefit of exposure to trainees on a wider array of CAM information resources [10]. Other studies have provided similar recommendations [11, 12]. Gudrun team emphasized on the importance on educating patients on the use of CAM as part of their treatment plan for cancer patients by the health care professionals whom to be educated at first hand $[13,14]$

The aim of this study was to assess the perceptions of different health care professionals (doctors, dentist, pharmacist, and nurses) towards HM and to determine whether they deem their HM-related knowledge base as adequate within their health care practice. Furthermore, an endeavor was made to identify the need of healthcare professional for further education programs relating to $\mathrm{HM}$ and the need for health caregivers to educate the patient on CAM before self-using. This information would ultimately form a framework to provide health practitioners with useful information to plan educational programs relating to HM. This is the first time, to our knowledge, that this has been undertaken within our institution and geographical region.

\section{MATERIALS AND METHODS}

Ethics

The study was conducted from January to July 2011, among health care professionals (doctors, dentist, pharmacist, and nurses) who had attended regular Continuous Medical Educational (CME) programs at Ras Al Khaimah Medical and Health Sciences University RAKMHSU. The study proposal with the questionnaire were submitted to the RAKMHSU Ethics Committee and the approval was obtained (no.4 April 2010). 


\section{Interest groups}

The 16-item questionnaire on the belief of health care professionals in herbal medicine was designed by the interdisciplinary task force. The interest groups comprised of faculty staff and students-situated within the RAKMHSU-were 5 in total with knowledge in medical and health disciplines. None of the interest groups members were contributors of the questions designed. Some of the questions were adopted and employed to reflect the culture of the gulf region towards HM $[15,16]$. As a first step, interest groups were formed for the initial development of the questionnaire. Participants within the interest groups rated each item in regards to its Herbal medicines values and subsequently whether these items were essential [17]. Content relevance was rated using a 5-point Likert-type scale with the following assessment scores: 1, not substantial; 2, substantial but needs major revision; 3, substantial but needs minor revision; and 4, fairly substantial and 5 , very substantial. Following further revisions, the interest groups reevaluated the resulting items for content validity. This process was iterated in a loop-like feedback fashion until all items received a ranking of $\geq 3$. The resultant questionnaire was pre-tested and revised by dedicated participants prior to wider utilization [18].

\section{Domains and questionnaire items}

Domain identification was initially performed by conducting a literature review using the term "complementary medicine and/or herbal medicine" and searching the Pubmed database [11, 19]. Concepts were identified and selected from the available literature and included: uses of herbal medicines; types of herbal medicines; uses of natural products for pregnancy and gestation; sourcing herbal medicines; economic benefits of herbal medicines; patient education with regards to HM; definition of herbal products; herbal products in human health; natural products and health promotion; food-drug interaction; drug-drug interaction; sourcing natural products; efficacy or effectiveness of complementary medicines; and the importance of herbal medicines.

Questionnaire items were generated to capture the abovementioned themes. The resultant items were subsequently channeled back to the interest groups for the purpose of judgment-quantification.

\section{Final 16-item questionnaire}

The survey consisted of 5 questions relating to the pooling of personal information and 16 core questions which ultimately collated the behavioral, health and attitudinal information relating to survey participants who make use of HM. Core questions focused specifically on HM-related issues including purpose; outlets; efficacy; and attitudes to the practice of pharmacy as it relates to natural products. Response options varied depending on the type of question asked and included: multiple choices (3 questions); open-ended free text; and Likert-scaled responses, as shown in Appendix 1.

Participating subjects and the administration of the questionnaire

All subjects were aged $\geq 18 \mathrm{y}$ and consent was provided by the return of questionnaires or via direct interview. A heterogeneous sample of health care professionals (doctors, nurses, and pharmacists) was recruited in order to ensure a diverse range of attitudes, perceptions and self-use with regards to $\mathrm{HM}[20,21]$. Apart from the paper based-questionnaire-which is provided with the scientific materials folder of the CME-distribution of some paper based-questionnaires by hand via students volunteers [22] Participants belong to many nationalities, as shown in table 1.

Table 1: Demographic characteristic of complementary medicine questionnaire participants

\begin{tabular}{|c|c|c|}
\hline Demographic variable & No. & $(\%)^{*}$ \\
\hline \multicolumn{3}{|l|}{ Age } \\
\hline $18-30$ & 159 & 28.8 \\
\hline $31-40$ & 173 & 31.3 \\
\hline $41-50$ & 104 & 18.8 \\
\hline $51-60$ & 43 & 7.8 \\
\hline $61-70$ & 37 & 6.7 \\
\hline \multicolumn{3}{|l|}{ Gender } \\
\hline Male & 201 & 36.4 \\
\hline Female & 352 & 63.7 \\
\hline \multicolumn{3}{|l|}{ Nationality } \\
\hline Iraq & 12 & 2.2 \\
\hline Philippine & 11 & 2.0 \\
\hline Bangladesh & 2 & 0.4 \\
\hline Jordan & 15 & 2.7 \\
\hline Syria & 9 & 1.6 \\
\hline Egypt & 6 & 1.1 \\
\hline Palestine & 40 & 7.2 \\
\hline UAE & 64 & 11.6 \\
\hline Lebanon & 4 & 0.7 \\
\hline Sudan & 32 & 5.8 \\
\hline Pakistan & 35 & 6.3 \\
\hline Demographic Variable & No. & $(\%)^{*}$ \\
\hline Yemen & 4 & 0.7 \\
\hline India & 170 & 30.7 \\
\hline Others & 149 & 27.0 \\
\hline \multicolumn{3}{|l|}{ Marital status } \\
\hline Married & 390 & 70.5 \\
\hline Separated & 12 & 2.2 \\
\hline Widowed & 9 & 1.6 \\
\hline Never married & 114 & 20.6 \\
\hline
\end{tabular}

${ }^{*}$ Percentage of total respondents

\section{Data analysis}

Standard descriptive statistics were used to summarize the data. Statistical significance was set at $P<0.05$, using chi-square test. Missing data was taken into account in all percentage calculations in order to retain accuracy. All statistical analyses were performed using the IBM-compatible software package SPSS (version 15.0).

\section{RESULTS AND DISCUSSION}

Demographic data of participants relating to age, gender, nationality, occupation and marital status are shown in table 1 . In total, 1000 questionnaires were distributed and health care providers $(n=781)$ responded such that the response rate was $78 \%$. With regard to the responders, $71 \%(\mathrm{n}=553)$ indicated previous use of herbal 
medicine of these, only 325 participants believed (i. e acceptance to use and consume HM) in herbal medicine while 228 did not. With regard to participants who did not believe in the use of herbal medicine, their responses are shown in fig. 1.

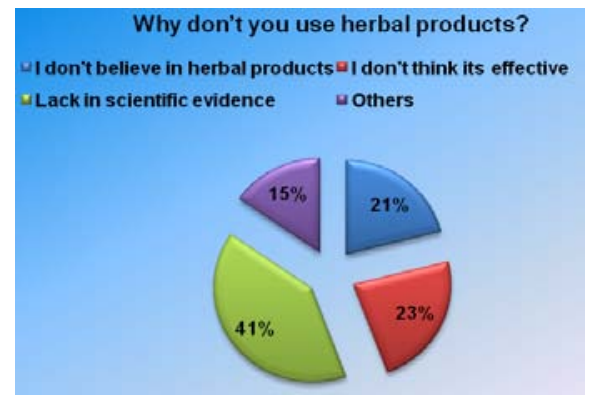

Fig. 1: Illustrates percentage of participants who do not use (believe) in herbal products

With regard to responders who believed in the use of herbal medicine $(\mathrm{n}=325)$, motivations for utilizing these types of medicines included: herbal medicine keeping them healthy (16.9\%); fewer side effects compared to conventional medicine (12.2); treatment of specific diseases $(11.75 \%)$; belief that the health condition is not serious enough to take prescription medicines $(6.5 \%)$; prevention of disease (4.8\%); herbal medicines work better or just as well as other medicines $(2.35 \%)$; recommended by others (1.6\%); and other reasons such as self-satisfaction (1.8\%). Self-satisfaction refers to the attitude of participants towards herbal medicine.

Questionnaire responses indicated the following most popular herbal medicines used: honey (35.9\%); green tea $(30.9 \%)$; olive oil (29.29\%); ginger (30\%); garlic (25.6\%); and cinnamon $(19.3 \%)$. In addition, responses showed that herbal medicines were most commonly used for: gastrointestinal tract disease $(29.47 \%)$ respiratory disease (22.6\%); hypercholesterolemia (12.6\%); skin disease $(10.3 \%)$; urinary tract infection $(8.6 \%)$; to improve stamina; diabetes (5.9\%); and cardiovascular disease (4.3\%). Respondents most commonly sourced herbal medicine information from: experiences of friends and family members (33.2\%); media including television, magazines, and radio (29.4\%); product labeling (16.9\%); and advice from other health practitioners (11.2\%).

For the questionnaire-based cost analysis relating to purchasing of herbal medicines, $57.3 \%$ of participants provided responses (317 of 553). In total, $22.2 \%, 14.2 \%$, and $9.7 \%$ of participants indicated that their personal herbal product-related monthly expenditure ranged between 0 and 70, 71 and 150, and $\geq 151$ United Arab Emirates Dirham, respectively.

Participants also recorded recommendations for sourcing herbal medicines. In total, $58 \%$ (321 of 553) of questionnaire responders recorded their findings. It was found that $25.3 \%$ of participants made use of herbal medicines due to personal experience, $20.1 \%$ made reference to recommendations by friends and family members, $5.2 \%$ cited recommendations by other health care professionals, and $4.5 \%$ indicated other types of recommendations.

One item of the questionnaire focused on analyzing whether participants considered themselves knowledgeable about herbal medicines which they used. With regard to this, 47\% (262 of 553) indicated that they were, $9.2 \%$ admitted to being completely unaware, while $2.1 \%$ of participants were unsure.

Participants were also questioned as to whether natural medicines which they used could be replaced with conventional medications in order to achieve the same clinical benefits. In total, $58.7 \%$ (325 of 553 ) of participants were responders and $40.1 \%$ of health care professionals never replaced natural medicines with conventional medication. In contrast, $18.6 \%$ have replaced natural medicines with conventional medication.

A safety analysis indicated that herbal medicines were safe in $44.3 \%$ (245 of 553) of participants who had previously used them and never encountered any adverse events. This was followed by $9.9 \%$ (55 of 553) of participants experiencing minor adverse events. Almost none of the participants experienced moderate or severe adverse events.

The effectiveness of herbal medicines was assessed with the use of a Likert scale. With regard to participants who had previously used herbal medicines $(n=553), 20.6 \%$ indicated that herbal medicines were moderately effective, $19.3 \%$ reported them to be mildly effective, and $17.35 \%$ were found to consider herbal medicines as highly effective. In addition, $24.05 \%$ of respondents purchased herbal medicines from pharmacies, $22.4 \%$ from supermarkets, and $10.3 \%$ from health food stores.

With regard to participants who had previously used herbal medicines $(n=553)$, responders indicated that different methods should be used to increase public awareness about these products. Out of 226 responders, 135 participants indicated that clinically supporting evidence is needed via published research, 59 participants believes in increasing the skills of the pharmacist, and 55 suggested incorporating relevant courses in the curriculum.

Out of 373 participants, 195 were medically insured while 178 had no medical insurance. Out of a total of 458 responders, 346 were healthy while 85 were affected with a medically diagnosed condition. Finally, out of 449 responders, 376 and 73 participants had not used and used prescription medication, respectively.

Table 2 shows the willing to use herbal medicines in relation to participants' knowledge of herbal medicines, private health insurance, use of prescription medications, belief in herbal medicines effectiveness and suffering of any health conditions. Respondents showed a significant willingness to use herbal medicines when it comes to participant knowledge and the ownership of private health insurance.

Table 2: Association between willing to use herbal products and participants' knowledge of herbal products, private health insurance, use of prescription medications, belief in herbal products effectiveness and suffering of any health conditions

\begin{tabular}{|c|c|c|c|c|}
\hline \multirow[t]{2}{*}{ Participants response } & \multicolumn{3}{|c|}{ Respondents who are willing to use herbal products } & \multirow[t]{2}{*}{ Fisher's exact $p$} \\
\hline & $\begin{array}{l}\text { Yes } \\
n=103\end{array}$ & $\begin{array}{l}\text { No } \\
n=222\end{array}$ & $\begin{array}{l}\text { Total } \\
n=325\end{array}$ & \\
\hline \multicolumn{5}{|c|}{ Do you have knowledge about herbal products? } \\
\hline Yes & 262 & 103 & 365 & \multirow[t]{2}{*}{$<0.0001^{*}$} \\
\hline No & 51 & 222 & 273 & \\
\hline \multicolumn{5}{|c|}{ Do you have private health insurance? } \\
\hline Yes & 195 & 103 & 298 & \multirow[t]{2}{*}{$<0.0001^{*}$} \\
\hline No & 178 & 222 & 400 & \\
\hline \multicolumn{5}{|c|}{ Do you take any prescription medications? } \\
\hline Yes & 73 & 103 & 176 & \multirow{2}{*}{$<0.0001^{*}$} \\
\hline No & 376 & 222 & 598 & \\
\hline \multicolumn{5}{|c|}{ Do you think that herbal products are effective? } \\
\hline Yes & 317 & 103 & 420 & \multirow[t]{2}{*}{$<0.0001^{*}$} \\
\hline No & 11 & 222 & 233 & \\
\hline \multicolumn{5}{|c|}{ Do you have any medical conditions? } \\
\hline Yes & 85 & 103 & 188 & \multirow[t]{2}{*}{$<0.0001^{*}$} \\
\hline No & 373 & 222 & 595 & \\
\hline
\end{tabular}

$*$ P value significant $\leq 0.0001$ 
Table 3 shows the number of respondents to each question in the survey. The total number of participants who responded to the questionnaire was 553. However, the actual respondents to each question varies which might be attributed to the nature of participant in terms of nationality, culture and socioeconomic factors.

Table 3: The response of participants for each question (note: 3 questions of multiple choice answers are not included)

\begin{tabular}{|c|c|c|c|}
\hline Question & $\begin{array}{l}\text { Number of } \\
\text { participants answered }\end{array}$ & $\begin{array}{l}\text { Number of participants } \\
\text { did not answer }\end{array}$ & $\begin{array}{l}\text { Total of } \\
\text { participants }\end{array}$ \\
\hline Why don't you use herbal products? & 228 & 325 & 553 \\
\hline Why are you taking herbal products? & 325 & 228 & 553 \\
\hline What is your expenditure on herbal products per year? & 317 & 236 & 553 \\
\hline Who usually recommends the herbal products you take? & 321 & 232 & 553 \\
\hline Do you have knowledge about herbal products? & 325 & 228 & 553 \\
\hline $\begin{array}{l}\text { Did you have any experiences of adverse reactions, drug-drug } \\
\text { interactions and contra-indicated from using herbs products? }\end{array}$ & 309 & 244 & 553 \\
\hline Where do you purchase your supplies and supplements? & 325 & 228 & 553 \\
\hline $\begin{array}{l}\text { Have you ever used herbal products to replace prescription or OTC } \\
\text { medicines? }\end{array}$ & 325 & 228 & 553 \\
\hline $\begin{array}{l}\text { How do you score the "effectiveness" of herbal products according to } \\
\text { your experiences? }\end{array}$ & 338 & 215 & 553 \\
\hline $\begin{array}{l}\text { What is your suggestion in order to increase public awareness about } \\
\text { herbal products? }\end{array}$ & 260 & 293 & 553 \\
\hline Do you have private health insurance? & 373 & 180 & 553 \\
\hline Do you have any medical conditions? & 458 & 95 & 553 \\
\hline Do you take any prescription medications? & 449 & 104 & 553 \\
\hline
\end{tabular}

The study indicated that the majority of responders believed in HM and used it mostly for the treatment and prevention of different diseases, due to its associated lesser incidence of adverse events, and for keeping participants healthy. These findings were similar to those found in a Swiss primary care study [16]. Green tea, olive oil, ginger, garlic, and cinnamon were among the most common herbal medicines used. Unfortunately, when participants were asked in one of the open-ended questions what type of herbal medicines they specifically use, honey was indicated as the most popular choice which indicates a lack of knowledge in discerning between natural and herbal medicines. This is undoubtedly an area where pharmacists can educate and increase awareness amongst health care professionals and other members of society. A small proportion of participants believed that HM has lesser efficacy in the treatment of diabetes and other cardiovascular diseases.

The main source of herbal medicine information for health care professionals appeared to be experiences of friends and family members as well as reports by the media. The majority of participants reported that the cost of HM is relatively low compared to conventional medication.

The study showed that a proportion of responders had inadequate knowledge relating to herbal medicines. Regardless of this fact, the majority of participants believed that HM is safe and is associated with minimal adverse events. This is concordant with the findings reviewed by Bent in 2008 [23]. In regard to the training on herbal medicines, US department of health recommends that more has to be done by health professionals to provide validated information to traditional healers and patients on the judicious use of herbal remedies that will reduce harm through side effects, interactions and other factors.

The majority of health care professionals perceived $\mathrm{HM}$ as moderately effective which could be due to awareness or knowledge about HM. Similarly, the presence of health care professionals who perceive HM to be less effective may be due to lack of familiarity with this treatment choice. Such familiarity could be facilitated by undertaking relevant research and increasing the herbal-related dispensing skills of the pharmacist. The latter could be achieved by incorporating relevant courses within the pharmacy curriculum as has been previously suggested [24]. Undoubtedly, nonstandardization of herbal and complementary medication due to differences in global climates and taxonomy may make international standardization of such courses difficult to achieve.

In total, $\sim 40 \%$ of participants never replaced or considered replacing natural products with conventional medication. This may be due to the use of natural products in treatment scenarios where the choice of conventional medication may be more limited than usual such as in enhancing fertility $[25,26]$.

Overall, responders reported a willingness to integrate conventional and HM practices within clinical care. However, a small percentage of participants indicated that $\mathrm{HM}$ has no true meaningful clinical efficacy. This may be due to a lack of information about currentlyavailable HM-focused evidence-based research. It may, therefore, be advisable to undertake more clinical trials to reinforce the use of herbal medicines worldwide [27].

The majority of participants believed that health care professionals should be able to advise their patients about HM, particularly health care professionals whose practice is localized within a rural setting [28]. In order to achieve this, pharmacy curricula should incorporate modules focusing on HM practices. Participants reported that the lack of training and scientific evidence are the greatest barriers to the clinical use of HM. Therefore, curricula should be designed in order to overcome these barriers $[29,30]$.

The study findings provide some evidence for the association between the knowledge that health care professionals have about $\mathrm{HM}$ and perceived effectiveness as well as safety. This data can provide a stepping stone for justifying the development of curricula to promote the knowledge transfer as well as efficacy and safety of using HM in a clinical setting [31, 32].

The limitations of the current study include the validity and reliability of the self-reported data and the generalizability of the findings to the overall population. The martial status may have a social and economic impact on herbal medicines consumed. The cross-section of participants sampled may not be representative of the general population since self-administered surveys in English are more likely to appeal to participants with an inherent interest and/or strong opinion in the topic and above-normal literacy in the language of the questionnaire.

For future, it may be useful for health care professionals to design and implement policies and programs that meet the needs of patients within their region and the world at large in a culturally sensitive manner. This will be addressed by authors through a formative questionnaire for some aspects of herbal medicine uses in UAE.

\section{CONCLUSION}

The findings of this study indicate that health care professionals believe in using HM for their needs and have a responsibility to 
provide information on HM to their patients. However, the current consensus among the respondents is that current HM-focused awareness among participants is inadequate for such an application.

\section{LIMITATIONS}

1- Logistics related to the distribution of the questionnaire

2- Access to the health care professionals in other emirates

3- The sample size

\section{AUTHORS CONTRIBUTIONS}

Amad M. Al-Azzawi, Nehad Mehdi, Alyaa G. Al-Juboori and Omar Sarheed contributed in the design, planning, execution and data analysis of the questionnaire as well they contributed in the writing of the manuscript.

Anam Ejaz and Haneen Ali contributed in the design and data collection and analysis.

\section{CONFLICTS OF INTERESTS}

All author have none to declare

\section{REFERENCES}

1. Erah PO. Herbal medicines: challenges. Trop J Pharm Res 2002;2:53-4.

2. Skalli S, Zaid A, Soulaymani R. Drug interactions with herbal medicines. Ther Drug Monit 2007;29:679-86.

3. Wapf V, Busato A. Patients' motives for choosing a physician: comparison between conventional and complementary medicine in swiss primary care. BMC Complement Altern Med 2007;7:41.

4. Chang ZG, Kennedy DT, Holdford DA, Small RE. Pharmacists' knowledge and attitudes toward herbal medicine. Ann Pharmacother 2000;34:710-5.

5. Miller LG, Hume A, Harris IM. White paper on herbal products. Pharmacotherapy 2000;20:877-91.

6. Lisk C. Food for thought in a doctors' knowledge of herbal medicines needs to be better. Acute Med 2012;11:134-7.

7. Bjerså K, Stener Victorin E, Fagevik Olsén M. Knowledge about complementary, alternative and integrative medicine (CAM) among registered health care providers in swedish surgical care: a national survey among university hospitals. BMC Complement Altern Med 2012;12:12-42.

8. Shah B, Siganga W, Mallya U, Shah S. Pharmacy student perspectives on classroom education about herbal supplements. Am J Pharm Educ 2005:69:102. Article: 80

9. Harris IM, Kingston RL, Rodriguez R, Choudary V. Attitudes towards complementary and alternative medicine among pharmacy faculty and students. Am J Pharm Educ 2006;70:129.

10. Lie DA, Boker J. Comparative survey of complementary and alternative medicine (CAM) attitudes, use, and informationseeking behavior among medical students, residents and faculty. BMC Med Educ 2006;6:58.

11. Tiralongo E, Wallis M. Attitudes and perceptions of Australian pharmacy students towards complementary and alternative medicine-a pilot study. BMC Complement Altern Med 2008;8:2.

12. Braun LA, Tiralongo E, Wilkinson JM, Spitzer O, Bailey M, Poole $\mathrm{S}$, et al. Perceptions, use and attitudes of pharmacy customers on complementary medicines and pharmacy practice. BMC Complement Altern Med 2010;10:38.

13. Mathew E, Muttappallymyalil J, Sreedharan J, John LJ, John J, Mehboob M, et al. Self-reported use of complementary and alternative medicine among the health care consumers at a tertiary care center in Ajman, United Arab emirates. Ann Med Health Sci Res 2013;3:215-9.
14. Gudrun EK, Corina G. Information and training needs regarding complementary and alternative medicine: a cross-sectional study of cancer care providers in germany. Integr Cancer Ther 2016;17:2.

15. Onyiapat JL, Okoronkwo IL, Ogbonnaya NP. Complementary and alternative medicine use among adults in Enugu, Nigeria. BMC Complement Altern Med 2011;11:19.

16. Lhamo N, Nebel S. Perceptions and attitudes of bhutanese people on sowa rigpa, traditional bhutanese medicine: a preliminary study from Thimphu. J Ethnobiol Ethnomed 2011;7:3.

17. Lynn M. Determination and quantification of content validity. Nurs Res 1985;35:382-5.

18. Schneider CD, Meek PM, Bell IR. Development and validation of IMAQ: integrative medicine attitude questionnaire. BMC Med Educ 2003;3:5.

19. Junaid R, Abaas M, Fatima B, Anis I, Hussain M. Attitude and practice of patients and doctors towards complementary and alternative medicine. Pak Med Assoc 2012;6:865-8.

20. Adams J, Sibbritt D, Broom A. A comparison of complementary and alternative medicine users and use across geographical areas: a national survey of 1,427 women. BMC Complement Altern Med 2011;11:85.

21. Creswell JW. Research design: qualitative, quantitative, and mixed methods approaches. $2^{\text {nd }}$ ed. London: Sage; 2003.

22. Greene JC, Caracelli VJ, Graham WF. Toward a conceptual framework for mixed-method evaluation designs. Educ Eval Policy Anal 1989,11:255-74.

23. Bent S. Herbal medicine in the United States: review of efficacy, safety, and regulation. J Gen Intern Med 2008;23:854-9.

24. Hasan SS, Yong CS, Babar MG. Understanding, perceptions, and self-use of complementary and alternative medicine (CAM) among Malaysian pharmacy students. BMC Complement Altern Med 2011;11:95.

25. Pokladnikova J, Lie D. Comparison of attitudes, beliefs, and resource-seeking behavior for CAM among first-and third-year czech pharmacy students. Am J Pharm Educ 2008;72:24.

26. Rayner JA, McLachlan HL, Forster DA, Cramer R. Australian women's use of complementary and alternative medicines to enhance fertility: exploring the experiences of women and practitioners. BMC Complement Altern Med 2009;9:52.

27. Edirne T, Arica SG, Gucuk S. Use of complementary and alternative medicines by a sample of Turkish women for infertility enhancement: a descriptive study. BMC Complement Altern Med 2010;10:11.

28. Ameh SJ, Obodozie 00, Abubakar MS, Garba M. Current phytotherapy-an inter-regional perspective on policy, research and development of herbal medicine. J Med Plants Res 2010;4:1508-16.

29. Cuellar N, Aycock T, Cahill B, Ford J. Complementary and alternative medicine (CAM) use by African American (AA) and Caucasian American (CA) older adults in a rural setting: a descriptive, comparative study. BMC Complement Altern Med 2003;3:8.

30. Harun-Or-Rashid. Perceptions of the Muslim religious leaders and their attitudes on herbal medicine in Bangladesh: a crosssectional study. BMC Res Notes 2011;4:366.

31. AlZahrani SH, Bashawri J, Salawati EM, Bakarman MA. Knowledge and attitudes towards complementary and alternative medicine among senior medical students in King Abdulaziz University, Saudi Arabia. Evid Based Complement Alternat Med 2016. Doi:10.1155/2016/9370721

32. Nisha P, Sheela S. Nutritive value, acceptability, antioxidant activity and storages hibiscus rosa sinensis incorporated ready to eat powders. Int J Curr Pharm Res 2015;7:89-91. 